

\title{
À guisa de posfácio
}

\author{
Renato Dagnino
}

DAGNINO, R. À guisa de posfácio. In: Tecnologia Social: contribuições conceituais e metodológicas [online]. Campina Grande: EDUEPB, 2014, pp. 315-318. ISBN 978-85-7879-327-2. Available from

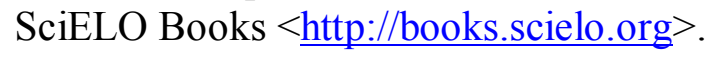

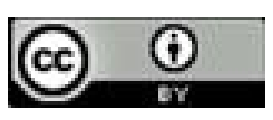

All the contents of this work, except where otherwise noted, is licensed under a Creative Commons Attribution $\underline{4.0 \text { International license. }}$

Todo o conteúdo deste trabalho, exceto quando houver ressalva, é publicado sob a licença Creative Commons Atribição 4.0.

Todo el contenido de esta obra, excepto donde se indique lo contrario, está bajo licencia de la licencia $\underline{\text { Creative }}$ Commons Reconocimento 4.0. 


\section{À guisa de posfácio}

\section{Neodesenvolvimentistas versus "solidaristas": um debate necessário}

A agenda das políticas públicas que envolvem a produção de bens e serviços vem recolocando, em cena, o debate sobre a relação entre crescimento econômico e desenvolvimento. O primeiro entendido como aumento do PIB per capita e o segundo como o processo de elevação do bem-estar do conjunto da sociedade.

De um lado, encontra-se a proposição neodesenvolvimentista. Embora ela tenda a negar que o crescimento é uma condição suficiente para o desenvolvimento, afirma categoricamente que o crescimento é uma condição necessária para o desenvolvimento. E, para promover o crescimento, subsidia o aumento da produção de bens e serviços pelas empresas.

Não me parece necessário detalhar essa proposição uma vez que é uma reedição - fragilizada pelos contextos tecnoprodutivos nacional e mundial e com bem menor probabilidade de êxito - daquela que orientou nossa política produtiva até o neoliberalismo.

Ainda sem batizá-la, enuncio as noções em que fundamentam a outra proposição. A primeira é a de que esses dois processos respondem a duas dinâmicas. A da produção e circulação de bens e serviços, ou do mercado (no capitalismo) responde pelo crescimento enquanto que o desenvolvimento é de responsabilidade do Estado mediante suas políticas sociais.

O crescimento econômico é um resultado de atividades de iniciativa da classe proprietária. Ele não leva necessariamente (e a experiência dos países periféricos o evidencia) ao desenvolvimento. O desenvolvimento não pode prescindir de políticas sociais. Aquelas que a classe proprietária poderia chamar "antieconômicas" e que compensam a tendência concentradora da dinâmica do "mercado". Incluindo aqui o seu componente gerado pelas políticas econômicas, que talvez devessem ser chamadas de "antissociais", que são implementadas pelo Estado.

As políticas sociais financiadas pelos recursos advindos da taxação dessas atividades, em adição ao que ganham os vendedores de força de 
trabalho, possibilitam a elevação do bem-estar do conjunto da sociedade; ou seja, o desenvolvimento.

A segunda noção em que se fundamenta a posição crítica ao neodesenvolvimentismo é a de que embora o crescimento tenda a facilitar a ocorrência do desenvolvimento, ele não é uma condição necessária. $\mathrm{O}$ que faz é gerar um fluxo de renda que pode ser realocado na margem, mediante a ação do Estado, sem mexer no estoque de riqueza da classe proprietária; sem "cutucar a onça...".

A terceira noção, que centraliza o debate, relaciona-se à maneira como as políticas sociais buscam promover o desenvolvimento atuando sobre a dinâmica do "mercado". Na sua crítica ao neodesenvolvimentismo, esta posição compara o sistema formado por essas duas dinâmicas com um conjunto de duas bombas que funciona uma contra a outra. Altamente ineficiente, ele dissipa energia e aumenta a entropia do sistema social em que está inserido.

A primeira bomba - dinâmica do "mercado" - atua em nosso tecido socioprodutivo, em que tem lugar a produção de bens e serviços a partir da propriedade concentrada dos meios de produção (dos empresários no capitalismo e da burocracia estatal, como aconteceu no socialismo real). $\mathrm{O}$ que conduz a um processo de produção sociotécnica e espacialmente concentrado; que por sua vez induz à concentração do excedente gerado e da renda, ao inchamento das cidades, à maximização do dano ambiental, ao aumento da dependência cultural, econômica e tecnocientífica etc.

Sua eficiência, avaliada como tende a ser por critérios internos às empresas, que por construção deixam de lado as externalidades "positivas" ou "negativas", parece ser muito elevada. O fato de que numa economia que pratica, durante tanto tempo, uma elevadíssima taxa de juro, ainda, exista quem aloque recursos para a produção é uma evidência de que essa dinâmica proporciona às empresas uma das mais altas taxas de lucro do mundo.

A segunda bomba atua através das políticas sociais do nosso Estado latino-americano que, depois de décadas dirigido por governos pouco preocupados com o desenvolvimento, vem tentando distribuir renda. Ação que tem esbarrado numa estrutura estatal conformada para atender às demandas da classe proprietária e numa correlação de forças políticas desfavorável, advinda de nossa ancestral e enorme concentração de poder econômico e político. Além de colocar continuamente ameaças à governabilidade, ela impossibilita uma reforma tributária que seria condição para tirar da informalidade quase metade da nossa população que não possui o suficiente para viver dignamente. 
A eficiência dessa segunda bomba parece ser muito baixa. $O$ fato de que nem mesmo a cobrança de impostos das empresas e a adoção de uma escala progressiva do imposto de renda etc., têm sido logradas, dá uma ideia da pouca "eficiência" do nosso Estado para distribuir o excedente. Contrastes como o que existe entre o programa (redistributivo) Bolsa Família, que custa $0,4 \%$ do PIB e beneficia 13 milhões de famílias, e que convive com outro "programa" (concentrador) Serviço da Dívida Pública, que custa até $8 \%$ do PIB e beneficia 20 mil famílias são evidências disso.

A outra posição que participa do debate sobre a relação crescimento-desenvolvimento, ao contrário da proposição neodesenvolvimentista, que se baseia na noção de que a convivência dessas duas dinâmicas é, mais do que necessária, inarredável, defende que nossas vidas dependem da desconstrução desse sistema. E aponta que já está em construção outro sistema, o da Economia Solidária que, ao contrário do crescimento competidor (o que não quer dizer competitivo), o neodesenvolvimentismo implica, propõe a solidariedade, razão pela qual eu a passo chamar de "solidarista".

Ela propõe o fortalecimento do um arranjo societário baseado na organização do movimento social que está emergindo da Economia Informal onde tendem a situar-se os quase 200 milhões de brasileiros "suplementares" aos cerca de 40 que possuem a carteira assinada que os qualifica como "incluídos" na Economia Formal. Esse arranjo agrupa os empreendimentos solidários baseados, ao contrário das empresas privadas e estatais, na propriedade coletiva dos meios de produção, em que trabalhadores associados se dedicam à produção de bens e serviços de modo autogestionário e desconcentrado.

Embora ainda submetidos à dinâmica do "mercado", comprando ou vendendo para a Economia Formal, esses empreendimentos tenderão a formar cadeias produtivas cada vez mais densas, completas e entrelaçadas e crescentemente a ela autônomas. Orientados para bens e serviços para consumo dos trabalhadores e de suas famílias, para a produção em outros empreendimentos solidários e, também, dos cidadãos em geral que os recebem via a intermediação do poder de compra do Estado, eles se consolidam como oportunidades de criação de trabalho e renda.

Os "solidaristas" propõem um decidido apoio governamental aos empreendimentos solidários, coerente, pelo menos, ao seu papel de absorção daqueles milhões de brasileiros que numa jobless and jobloss economy dificilmente serão absorvidos pela Economia Formal. Na medida em que recebam do governo benefícios, qualitativamente semelhantes e 
quantitativamente proporcionais aos que hoje recebem as empresas, inclusive os relacionados à capacitação naquelas habilidades e competências que efetivamente necessitam para se tornarem sustentáveis, eles poderão funcionar como "porta de saída" para os programas compensatórios.

À medida que se consolidem, irão desenvolvendo, mediante a adequação sociotécnica da tecnociência convencional produzida para e pelas empresas, a Tecnologia Social que os tornará - econômica, social, cultural e ambiental - crescentemente sustentáveis. Embora necessitem, como o fazem as empresas, do apoio do Estado, os empreendimentos solidários poderão, tendencial e parcialmente, dele prescindir. No limite, não mais serão necessários os recursos que ele retira mediante imposto da classe proprietária para compensar, com as políticas sociais, aquilo que a classe trabalhadora deixa de receber pelo trabalho (não pago) que realiza. Passará a ser desnecessária essa função que o Estado desempenha para garantir, pela via do gasto social, a exploração do trabalhador em sociedades em que a propriedade dos meios de produção e do conhecimento não é coletiva.

Será consideravelmente diminuído o enorme custo - econômico, social, tecnocientífico e ambiental - associado à concentração que existe nos planos da produção e circulação de bens e serviços e aos mecanismos de subsídio, transporte, comércio, propaganda, regulação, taxação, garantia da propriedade etc. que elas envolvem e que a sociedade, diretamente ou através do Estado, incorre.

Também será desnecessária a sisífica tarefa dos que, a partir do Estado e fora dele, buscam impedir que o mercado destrua o planeta e malbarate ainda mais aquilo que de humano, todavia, possui a nossa humanidade. $\mathrm{O}$ crescimento econômico resultante da produção aumentada dos empreendimentos solidários será, afinal, o próprio desenvolvimento que queremos. 
Sobre o livro

\author{
Capa e Projeto Gráfico Carlos Serrao \\ Normalização Jane Pompilo dos Santos \\ Revisão Carlos Neto \\ Impressão Gráfica Universitária da UEPB \\ Formato $16 \times 23 \mathrm{~cm}$ \\ Mancha Gráfica $9,5 \times 13 \mathrm{~cm}$ \\ Tipologia utilizada Minion Pro 12/14,4 pt \\ Papel Pólen $75 \mathrm{~g} / \mathrm{m}^{2}$ (miolo) \\ e Cartão Supremo $250 \mathrm{~g} / \mathrm{m}^{2}$ (capa)
}


Este segundo volume da Série Tecnologia Social deriva do interesse que o tema tem despertado em professores, estudantes, gestores públicos e participantes de movimentos sociais com quem seu autor vem dialogando. B de sua percepçäo de que a sociedade mais justa, igualitária e ambientalmente sustentável que desejam demanda uma aliança da comunidade de pesquisa que hegemoniza as políticas cognitivas (da Ciência e Tecnologia e do Ensino) e dos trabalhadores que intentam sair da informalidade para a Economia Solidária. Deter a exclusão que penaliza a maioria da população mundial e caminhar na direçâo de uma sociedade fundamentada numa outra tecnociência sáo a raiz dos argumentos sintetizados no conceito de Tecnologia Social. Nas palavras do autor, "o livro visa somar-se ao trabalho de um número crescente de latino-americanos que estăo construindo a plataforma cognitiva de lançamento - a Tecnologia Social - de uma nova proposta societária - a Economia Solidária. Testemunham a importância desse trabalho as opinióes de pesquisadores que por serem bem conhecidos na região dispensam apresentạ̧óes. 